\title{
The natural course of DSM-IV somatoform disorders and syndromes among adolescents and young adults: a prospective-longitudinal community study
}

\author{
Roselind Lieb $^{1 *}$, Petra Zimmermann ${ }^{1}$, Robert H. Friis ${ }^{2}$, Michael Höfler ${ }^{1}$, Sven Tholen ${ }^{1}$, Hans- \\ Ulrich Wittchen ${ }^{1,3}$
}

1 Max Planck Institute of Psychiatry, Clinical Psychology and Epidemiology Unit, Kraepelinstr 2, 80804, Munich, Germany;

2 Department of Health Science, California State University, Long Beach, A, USA;

3 Department of Clinical Psychology and Psychotherapy, Technical University Dresden, Dresden, Germany

\section{Summary}

Objective. Although somatoform disorders are assumed to be chronic clinical conditions, epidemiological knowledge on their natural course based on representative samples is not available. Method. Data come from a prospective epidemiologic study of adolescents and young adults in Munich, Germany. Respondents' diagnoses $(\mathrm{N}=2548)$ at baseline and follow-up on average 42 months later are considered. The follow-up incidence, stability as well as selected baseline risk factors (sociodemographics, psychopathology, trauma exposure) for the incidence and stability of somatoform disorders and syndromes are prospectively examined. Diagnostic information was assessed by using the standardized Munich-Composite International Diagnostic Interview (M-CIDI). Results. Over the follow-up period, incidence rate for any of the covered somatoform diagnoses was $25.7 \%$. Stability for the overall group of any somatoform disorder/syndrome was $48 \%$. Female gender, lower social class, the experience of any substance use, anxiety and affective disorder as well as the experience of traumatic sexual and physical threat events predicted new onsets of somatoform conditions, while stability was predicted by being female, prior existing substance use, affective and eating disorders as well as the experience of a serious accident. Conclusions. At least for a substantial proportion of individuals, the overall picture of somatization seems to be relatively stable, but with fluctuation in the symptom picture over time. Being female, the experience of substance use as well as anxiety disorder seem to constitute risk factors for the onset of new somatoform conditions as well as for a stable course over time.

Keywords: Somatoform disorders / Adolescence / Epidemiology

\section{Introduction}

The key features of somatoform disorders as defined by latest edition of the American Psychiatric Association's Diagnostic and Statistical Manual of Mental Disorders (DSM-IV; [1]) are physical symptoms that are not fully explainable by a medical condition or by the effects of any substance or any other mental disorder. In the DSM-IV, subjects with presentations of medically unexplained symptoms are covered by the diagnostic group of somatoform disorders, which include somatization disorder as the prototype of somatoform disorders, hypochondriasis, pain disorder, conversion disorder as well as body dysmorphic disorder. Previous epidemiological studies on adults as well as on younger age groups have consistently shown that the prevalence rates for the full-blown somatoform disorders seem to be rather low (range: $0-2 \%$; see [5,9,10,12,20,21, 26,32,34,35]). Less restricted defined forms of somatization, subsumed in the DSM-IV under the rest category of "undifferentiated somatoform disorder" have been found to be much more common. An example is the 
abridged form of somatization labeled Somatic Symptom Index (SSI4,6) introduced by Escobar et al. [8], defined as four symptoms in males and six in females, for which lifetime rates between $3 \%$ in adolescents and young adults [21] and $4.4-20 \%$ in adults $[6,8,27]$ have been reported. Although these previous epidemiological studies have presented basic knowledge on the prevalence of somatoform disorders in the population, epidemiological data on the natural course of somatoform disorders in terms of incidence and stability as well as on factors associated with the natural course is sparse. This is remarkable, as assumptions about the natural course (i.e., chronicity) are even reflected in the current diagnostic criteria. For example, DSM-IV criteria emphasize the stability and chronicity of somatization disorder by defining this condition as a history of many physical complaints that begin before age 30 years and persist over a period of several years. As far as we are aware, there are only three studies in the literature that examined incidence and stability of somatoform disorders. The World Health Organization's Psychological Problems in General Health Care project examined incidence and stability of somatization in terms of the abridged SSI4,6 as well as somatoform symptoms prospectively over 12 months in primary care attenders [11]. Using the Composite International Diagnostic Interview (CIDI) as diagnostic instrument, researchers found that somatization according to SSI4,6 was persistent over a 12 -month period in $46 \%$ of the patients. For specific symptoms, persistence ranged from $52 \%$ (joint pains) to a low of $0 \%$ (amnesia). The 12-month incidence rate of the SSI4,6 was found to be 7\% in this clinical sample. As far as we are aware, this study is the only one in the literature that evaluated prospectively factors that are associated with stability and incidence of somatoform episodes over time. What they found was, that stability as well as incidence were predicted by selfrated poor overall health and by impaired work role. Incidence of new somatoform episodes was additionally predicted by depression at baseline. The second study evaluated prospectively the 4- to 5-year course of DSM-III-R hypochondriasis. Medical outpatients meeting DSM criteria for hypochondriasis were followed over a period of about 5 years [3]. Investigators found that hypochondriasis seems to be quite stable: $64 \%$ of the patients meeting diagnostic criteria at first assessment still met criteria 5 years later. The third study applied DSM-III criteria to inpatient and outpatient medical records and contacted 98 patients who met criteria for DSM-III conversion and somatization disorder about 4 years later [15]. A total of $76.3 \%$ of the former cases with somatization disorder and $68.8 \%$ of the cases with hypochondriasis again fulfilled diagnostic criteria after this 4-year follow-up period. Thus, for clinical samples, these three studies support the widely accepted view of somatoform disorders as chronic and persistent clinical conditions. However, clinical samples may be biased by self-selection factors that may influence the generalizability of the findings. As far as we are aware, virtually no studies using a non-clinical sample have investigated the natural course in terms of incidence, stability and factors related to incidence and stability of a broad range of somatoform disorders by using a prospective-longitudinal design. By using such an approach, this paper aims to study (a) the incidence and stability of somatoform disorders and syndromes, as well as (b) baseline sociodemographic factors, psychopathology and traumatic events that are associated with the incidence and stability of these clinical conditions in a representative population sample of 3021 adolescents and young adults. These subjects were aged 14-24 at the outset of the study and have been followed prospectively over a period of about 4 years.

\section{Materials and Methods}

\section{Overall design}

The data presented come from the Early Developmental Stages of Psychopathology Study (EDSP), a prospective-longitudinal survey designed to explore the prevalence and incidence, 
familial and other risk factors, comorbidity and course of mental disorders in a representative population sample of originally 3021 subjects aged 14-24 at baseline. The study consists of a baseline survey, two follow-up surveys, and a family history component. Detailed descriptions of the EDSP-design and field procedures are reported elsewhere [22,39].

\section{Sample and assessments}

The sample was drawn from the 1994 government registries of residents in Munich, Germany, expected to be 14-24 years of age at the time of the baseline interview in 1995. As the study was designed with special interest in early developmental stages of psychopathology, 14-15year-olds were sampled at twice the probability of 16-21-year-olds, and 22-24-year-olds were sampled at half this probability. At baseline (T0), a total of 3021 interviews were completed, resulting in a response rate of $71 \%$. The two follow-up assessments were completed after the initial baseline investigation, covering an overall period of 3-4 years (depending on the timing of the follow-up interviews, which were conducted after intervals of approximately 18 months). The first follow-up study (T1) was conducted on average 19.7 months (range $=15-25.6$ months) after the baseline study with a response rate of $88 \%$. Only the at baseline younger cohort (14-17 year-olds) were included in this wave. The second follow-up (T2), in which all baseline respondents were included again, was conducted in 1998/99 an average of 42 months (range $=34-50$ months) after baseline with a response rate of $84 \%(\mathrm{~N}=2548)$. Sociodemographic characteristics of the baseline (T0) and entire followup (T0-T2) sample have been published [22,31]. Briefly, at baseline, most of the respondents were attending school (89\%) and living with their parents $(97.8 \%)$. About $10 \%$ were in job training. The majority was classified as belonging to the middle class $(61.4 \%)$. Noteworthy changes in sociodemographic characteristics from baseline to second follow-up were found for school (follow-up: $42 \%$ attended school) and employment status (follow-up: $24 \%$ were in job training program and $12 \%$ were employed).

\section{Diagnostic assessment}

Diagnostic assessments in the baseline and the two follow-up investigations of the respondents were based on the computer-assisted version of the Munich- Composite International Diagnostic Interview (M-CIDI) that allows for the assessment of symptoms, syndromes and diagnoses of 48 mental disorders according to the DSM-IV along with information about onset, duration, severity and psychosocial impairment (M-CIDI; [40]). Diagnostic findings are obtained by using the M-CIDI/DSM-IV algorithms. For a detailed discussion of the M-CIDI, see Wittchen et al. [36] and also Lachner et al. [19]. At baseline, the lifetime version of the M-CIDI was used. At each follow-up, the M-CIDI interval-version was applied. In all assessments the M-CIDI was supplemented by a separate respondent's booklet that included several scales and questionnaires for assessing psychological constructs that are relevant to our study. A detailed overview and characterization of the constructs and assessment scales used has been presented elsewhere [13,22,38]. Reliability and validity findings of the M-CIDI $[19,25,36]$ along with descriptions of the M-CIDI format and coding conventions have been reported in detail elsewhere. For the main diagnostic category "any somatoform disorder" the one-week test-retest reliability, investigated in a general population sample of 60 adolescents and young adults [36] aged $14-24$ years, was acceptable $(\kappa=0.62)$. The validity - obtained by comparing M-CIDI-diagnoses of 68 randomly chosen patients to clinical diagnoses made by independent treating full licensed psychiatrists - was also sufficiently high $(\kappa=0.50)$. The sensitivity was $93.8 \%$, while the specificity was $71.2 \%$ [25]. 
Detailed descriptions of the training procedures, and fieldwork have been reported elsewhere $[22,39]$. Briefly, the highly experienced survey staff consisted of 57 clinical interviewers, most of whom were clinical psychologists. At baseline, 25 full-time professional health research interviewers were additionally included. Most of the interviewers had extensive experience in diagnostic interviewing including the CIDI and in the developmental work of the M-CIDI. All interviewers received two full weeks of training. In the fieldwork, most interviews were conducted in the home of the probands. To minimize errors and missing values, all interviewers were closely supervised by especially trained and clinically experienced M-CIDI editors. To reduce errors in the classification of symptoms as "somatoform", the editors reviewed case-by-case the responses to somatoform symptoms for which verbatim quotes were available. This editing was intended to judge whether or not the respondent's explanations as well as the interviewer's classification of the symptoms were plausible.

\section{Assessment of somatoform disorders}

The M-CIDI section of somatoform disorders along with its coding conventions has already been fully described in a previous publication [21]. This section starts with a checklist of 46 symptoms (according to DSM-IV or ICD-10), presented to obtain a fairly comprehensive account about all potential somatoform symptoms listed in DSM-IV and ICD-10 that the respondents might have had in their lifetimes. Each affirmed symptom is then explored with a series of probe questions that investigate whether a symptom is clinically significant and whether it can be entirely explained by a medical condition or the use of any substance (medication, drug or alcohol). Clinical significance is indicated either by seeking help from a medical doctor or other mental health professional, repeated intake of medication, or significant distress and interference with daily life because of the symptom. Only clinically significant symptoms are probed to determine whether they are fully explainable by a medical condition or the intake of any substance. The interviewer is directed to record and classify in a standardized way the subject's response as: (1) the symptom has always been the result of a physical disease, condition or injury; (2) the symptom has always been due to the intake of any substance; or (3) the symptom is not fully explainable by a medical explanation. A symptom is classified as not fully explainable when the subject confirms that the symptom has neither been always the result of a somatic disease or injury nor has always been caused by the intake of any substances. Consistent with DSM-IV-stipulation, only the latter symptoms are counted towards a diagnosis of somatoform disorder or syndrome. Further, each somatoform symptom is probed for age of first onset, whereas age of last occurrence is only probed if the diagnostic threshold for the respective diagnosis is reached. The M-CIDI incorporates DSM-IV diagnostic algorithms for somatization disorder, pain disorder, conversion disorder and hypochondriasis. Additionally, selected symptom coverage allows for an evaluation of dissociative disorder not otherwise specified (NOS), whenever a subject reports clinically significant dissociative symptoms. Further, the M-CIDI offers algorithms for two sub-threshold variations that do not meet the threshold for any specific DSM-IV somatoform disorder: (1) the abridged somatization definition SSI4,6 according to Escobar et al. [8], defined as four symptoms in males and six in females, and (2) the "undifferentiated somatoform/ dissociative syndrome (USDS)". The latter is assigned when the subject does not meet criteria for any other somatoform condition, but reports at least one clinically significant symptom with a minimum duration of 6 months and at least significant impairment during this period. Both of these conditions on the subthreshold diagnostic status are called "somatoform syndromes" in this report. Throughout the paper, unless otherwise stated, the DSM-IV diagnostic hierarchy rules were applied. Thus, for example, respondents who met criteria for somatization disorder or SSI4,6 were not assigned any other somatoform 
diagnosis, and USDS was only diagnosed when no specific somatoform disorder was present. Conversion disorder and dissociative disorder NOS were not defined as mutually exclusive.

\section{Assessment of baseline factors}

Besides the demographic variables age, gender, level of education and social class, the following factors were evaluated as baseline risk factors for the incidence and stability of somatoform disorders/syndromes: (a) prior history of mental disorders and (b) trauma exposure.

Prior history of mental disorders. The history of prior mental disorders included the lifetime history of the following

(1) any substance use disorders: alcohol abuse/ dependence, nicotine dependence, illicit drug abuse/ dependence;

(2) any affective disorder: bipolar disorders, major depression, dysthymia;

(3) any anxiety disorder: generalized anxiety disorder, panic disorder, agoraphobia w/o panic disorder, social phobia, specific phobia, obsessive compulsive disorder and posttraumatic stress disorder;

(4) any eating disorder: anorexia nervosa, atypical anorexia nervosa, bulimia nervosa and atypical bulimia nervosa.

\section{Trauma exposure}

The respondent baseline interview included the structured trauma exposure checklist of the post-traumatic stress disorder module of the M-CIDI [23]. This module covers traumatic experiences outside the range of normal human experience as defined in DSM-IV as for triggers of post-traumatic stress disorder. The specific particular childhood traumas evaluated in this paper include physical attacks, rape or sexual abuse, and life-threatening accidents. All other traumas (being kidnapped, natural catastrophe, witness, and other trauma) were grouped into the category "other trauma".

\section{Statistical analysis}

Analyses are based on the $\mathrm{N}=2548$ respondents who completed the whole study period (T0$\mathrm{T} 2$ ). For the younger cohort, the 14-17-year-olds at baseline (T0), the follow-up status is assessed from the aggregation of information obtained from the first (T0-T1) and second (T1-T2) follow-up interviews. For the older cohort, i.e., the respondents aged $>17$ at baseline, the follow-up status is assessed from the $\mathrm{T} 2$ questions, which refer to the time between $\mathrm{T} 0$ and $\mathrm{T} 2$.

The data were adjusted by age, sex and geographic location to match the distribution of the sampling frame. A more detailed description of the EDSP weighting procedure is presented elsewhere [39]. The Stata Software package [30] was used to compute robust confidence intervals required when basing analyses on weighted samples [28].

Logistic regressions with odds ratios (ORs) were used to describe associations between baseline factors and incidence and stability of somatoform disorders/ syndromes recognizing as confounding variables respondent's age and gender. In order to assess differences in associations with baseline risk factors and incidence and stability of somatoform disorders 
and syndromes between males and females as well as between the younger and the older cohort, the interactions with these two variables were additionally tested.

\section{Results}

Baseline prevalence, follow-up incidence and cumulative lifetime-incidence of DSM-IV somatoform disorders and syndromes

At baseline (first column of table I), $12.5 \%$ of the study sample reported that they had experienced at least one of the somatoform disorders or syndromes during their life. With $2.6 \%$, lifetime prevalence of any specific somatoform disorder was found to be rather rare. The most prevalent form of somatoform disorder was pain disorder $(1.7 \%)$, while others such as conversion disorder and dissociative disorder NOS were quite rare $(0.3 \%$ and $0.8 \%$, respectively). No case met the criteria for somatization disorder and hypochondriasis. Somatoform syndromes as defined in our study were estimated with a lifetime prevalence of 10.7 with USDS being the most prevalent subtype (9.0\%). Women reported higher rates for pain disorder $(3.2 \%$ vs. $0.3 \%$; OR $=13.9 ; 95 \% \mathrm{CI}=4.1-46.5)$ and for USDS $(12.1 \%$ vs. $5.9 \%$; $\mathrm{OR}=2.3 ; 95 \% \mathrm{CI}=1.6-3.2)$.

Among respondents who did not fulfill criteria for any of the assessed somatoform disorders and syndromes at baseline, the overall incidence rate for any of the covered diagnoses after the four year study period (T0-T2) was $25.7 \%$, with a relatively higher incidence of somatoform syndromes $(20.6 \%)$ when compared to full-blown somatoform disorders $(7.3 \%)$. Among the latter, pain disorder was found to be the most common incident form of somatoform disorders $(6.9 \%)$, while among somatoform syndromes, USDS was the condition with the highest incidence rate $(20.3 \%)$. No incidence cases of somatization disorder and hypochondriasis were observed. Again, women reported higher incidence rates for pain disorder $(10.7 \%$ vs. $3.2 \%$; $\mathrm{OR}=3.6 ; 95 \% \mathrm{CI}=2.4-5.4)$ and $\operatorname{USDS}(28.5 \%$ vs. $12.6 \%$; OR $=$ $2.7 ; 95 \% \mathrm{CI}=2.2-3.5)$ when compared with men. Highest cumulative lifetime incidence rates at T2 were obtained for pain disorder (8.5\%), SSI4,6 (2.6\%) and USDS (27.5\%), again with considerable gender differences.

Changes in caseness of somatoform disorders from baseline to follow-up (T0-T2)

Table II provides a cross-tabulation of the respondent's diagnostic status at baseline and follow-up.

The first column in table II indicates the probability of being well at follow-up. About half $(51.7 \%)$ of any somatoform disorder or syndrome at baseline completely remitted during follow-up period. Specifically, reporting none of the assessed somatoform disorders and syndromes during the follow-up period, was highest for cases with USDS and dissociative disorder NOS at baseline (58.6\% and 53.6\%, respectively). For the other diagnoses, remission rates were considerably lower with $34.5 \%$ for pain disorder, $10.6 \%$ for conversion disorder, and $25.7 \%$ for SSI4,6. Considering first the same diagnostic outcome during the follow-up period, stability was highest for pain disorder and USDS. About $30 \%$ of cases with this diagnosis at baseline fulfilled criteria again at follow-up (pain disorder: $29.7 \%$; USDS: $34.0 \%$, respectively). As presented in table II, there were considerable proportions of transitions between the different somatoform conditions assessed in the study.

This high stability within the overall diagnostic group of somatoform disorders/syndromes is also reflected by the conditional probability rates for the aggregated categories: almost $50 \%$ of 
all cases with any of the assessed somatoform disorders and syndromes reported any of these conditions again during follow-up, with a slightly higher stability rate for full-blown-disorders when compared to syndromes $(60.8 \%$ vs. $46.6 \%)$.

Because of the small sample sizes for most somatoform disorders, gender differences in stability were only evaluated for the aggregated diagnostic groups "any somatoform disorder or syndrome" as well as separately for "any somatoform disorder" and "any somatoform syndrome". Compared to men, women reported a considerably higher stability for the overall category of "any somatoform disorder or syndrome" $(53.9 \%$ vs. $34.3 \%$; OR $=2.2 ; 95 \% \mathrm{CI}=$ $1.2-3.9)$ as well as for the subgroup of "any somatoform syndrome" $(44.7 \%$ vs. $28.1 \%$; OR $=$ $2.0 ; 95 \% \mathrm{CI}=1.0-3.8)$. The stability for the subgroup of "any somatoform disorder" even was higher for women compared to men, though this difference reached no significance (25.8\% vs. $10.3 \%$; OR $=3.0 ; 95 \% \mathrm{CI}=0.3-24.5)$.

\section{Factors associated with incidence and stability}

Due to the small sample sizes in the specific disorders under consideration, baseline factors were examined with regard to the outcome of the aggregated group of any somatoform disorder/syndrome (table III).

Among the total group, being female, pre-existing substance use, affective and anxiety disorders as well as the experience of physical threat were significantly positively related to the incidence of somatoform disorders during the follow-up period. The experience of rape or sexual abuse was also found as predictor for the occurrence of new onsets of somatoform disorders/syndromes during follow-up, but this relationship was entirely due to females. We had no male who reported prior to baseline the experience of rape or sexual abuse and onset of somatoform disorders during follow-up. High social class as well as high educational level (Gymnasium) negatively predicted new onset of somatoform disorders during follow-up. Except for the experience of rape/sexual abuse mentioned above no differences in associations were found between males and females and between the younger and older cohort.

Stability of somatoform disorders/syndromes was predicted by being female, prior history of any substance, affective or eating disorder as well as the experience of a prior serious accident. None of the demographic variables was associated with stability of somatoform disorders. All associations were comparable for males and females. For rape/sexual abuse, the interaction could not be computed, due to the fact that there was no male that experienced either rape or sexual abuse prior to baseline and persistence of somatoform disorders during follow-up. No differences in associations were found between the younger and the older cohort.

\section{Discussion}

The main aim of this paper was to estimate incidence and stability of several somatoform disorders and syndromes, and to investigate prospectively factors that are associated with their incidence and stability over a time period of about 4 years.

Before discussing our findings, some limitations and caveats should be mentioned. (1) The EDSP is to our knowledge the first epidemiological study assessing a broader range of subthreshold and threshold somatoform conditions by using the redefined diagnostic definitions and criteria of DSM-IV. Thus, direct comparisons with other adolescent and adult community 
surveys based on other diagnostic criteria and instruments are cautioned. (2) The classification of symptoms into "clinically significant", "fully explainable" and "not fully explainable" categories must be interpreted with some caution for different reasons. In our study we do not have "objective" data (e.g. laboratory evaluations) or a physical examination, which would perhaps provide more "hard" indicators to decide the physical basis of the symptoms classified as somatoform. The assessment of somatoform symptoms is based on the standard M-CIDI probe questions and relies on the respondent's self-report. Symptoms are classified by health research interviewers or clinical psychologists, and-despite of the extensive training and supervision of the interviewers as well as the case-by-case reviews of the clinically experienced editors - we cannot totally be sure that none of the symptoms rated as "somatoform" had a medical explanation. (3) Although the M-CIDI diagnostic algorithms for threshold somatoform disorders have been tested for reliability and at least for some validity issues [25,36], the sub-threshold syndromes have not yet been explored psychometrically. (4) The diagnostic criteria for pain disorder were not entirely identical at baseline and follow-up. At baseline, subjects had to affirm that they were suffering at least 6 months due to the pain symptoms reported - that is, only "chronic" cases were counted. The 6-month criteria were not applied in the follow-up assessment what may have led to an overestimation of the incidence for pain disorder. (5) Although the respondents had two or three diagnostic evaluations, all information about symptoms relies on the subjects' responses and is based on their recollections. Recall bias could have affected in some cases the accuracy of information regarding clinical significance (e.g. use of medication, consulting a doctor). Further, inconsistencies in the recall of symptoms could have further affected the reliability of the symptom reports [29]. Within the context of these limitations, the following findings are noteworthy.

\section{Somatoform disorders and syndromes are widespread among adolescents and young adults}

Already our baseline results reveal that somatoform disorders and syndromes as defined by the M-CIDI/DSM-IV criteria are quite prevalent in adolescents. Like other researchers $[26,32,34,35]$ we found that the full-blown somatoform disorders are rather rare. However, somatoform syndromes beyond the diagnostic thresholds of the full-blown disorders (in our study defined according to the SSI4,6 as well as the USDS) seem to be considerably much more common. Taking the CIDIs convention to classify such sub-threshold syndromes by assigning the diagnosis whenever the person falls short of the mandatory criteria of the fullblown diagnosis, any of the somatoform syndromes assessed in the study was reported at baseline by about $10 \%$ of the respondents. In line with what other studies have reported $[2,16,17,41]$, such sub-threshold somatoform syndromes are much more common in females than in males. Although one might speculate about the clinical meaning of these sub-threshold syndromes, our previous analyses [21] as well as other studies $[7,14,18]$ could demonstrate increased rates of current and past disabilities as well as increased rates of health care utilization in individuals fulfilling diagnostic criteria of these syndromes. Thus, we believe that the assessed somatoform syndromes at this low diagnostic level are not merely trivial common complaints, but rather disabling conditions that deserve attention in research and clinical practice.

The longitudinal design of our study allowed us to study for the first time the incidence of a range of somatoform disorders and syndromes in a community sample of adolescents and young adults. The only direct comparable study that provided incidence rates is the World Health Organization's Psychological Problems in General Health Care project in the frame of which the incidence of somatization in terms of the abridged SSI4,6 was evaluated for a 12month interval [11]. Among primary care patients, the incidence of SSI4,6 was about 7\%. For 
the SSI4,6, our study found a considerably lower incidence rate over a 4-year period with about $1 \%$ of new cases with SSI4,6. We assume that this difference in the incidence of SSI4,6 might be explained by the older age range of the primary care sample as well as their clinical status. All our other incidence findings cannot be compared to previous findings - as such are not available. Nevertheless, we think that it is worthwhile to note that the overall incidence rate for pain disorder was about $7 \%$, suggesting that even among young adults this seems to be a quite frequent clinical condition.

Somatoform conditions are relatively stable and enduring, at least whenever the point of subthreshold diagnostic status is reached

The natural course of somatoform disorders and syndromes in adolescents and young adults revealed a relatively unfavorable outcome pattern. In terms of diagnostic and syndrome stability over a period of about 4 years, our data suggest that for a substantial proportion of individuals, both threshold and subthreshold somatoform conditions are stable and enduring conditions. Thus, about $60 \%$ of all baseline threshold cases and $45 \%$ of the baseline subthreshold cases were still cases 4 years later at least on the subthreshold diagnostic status. A comparison of these stability rates with the stability rates that we have found for anxiety and depressive disorders [37] indicates that the overall persistence of somatoform conditions is as high as the persistence of depressive disorder (1-year stability rate 32\% for sub-threshold cases and 51\% for threshold cases) and even higher than the persistence of anxiety disorders (1-year stability rate $20 \%$ for subthreshold cases and $31 \%$ for threshold cases). The finding that $45 \%$ of all baseline sub-threshold and threshold cases were again classified as at least subthreshold cases at second follow-up is comparable to the observations from Gureje and Simon [11], who reported that, across diverse cultural settings, about half of the patients with SSI4,6 somatization in primary care facilities continued to meet the criteria after 1 year. However, our data also suggest that the specific syndrome pictures must not generally be chronic, there rather seems to be a remarkable degree of fluctuation or "mobility" between the different somatoform conditions. Thus, the results argue conceptually rather for an "overall" phenomenon of somatization with variations in the picture of the specific syndromes over time.

\section{Risk factors for incidence and persistence}

Our longitudinal analyses found that being female, pre-existing substance use, affective and anxiety disorders as well as the experience of physical threat increases the risk for somatoform conditions in adolescents and young adults. Among females, also the experience of rape or sexual abuse was found as predictor for the occurrence of new onsets of somatoform disorders/ syndromes. We found also that high social class as well as high educational level (Gymnasium) is negatively associated with new onset of somatoform disorders during follow-up. As, to our knowledge, no previous study examined risk factors for somatoform disorders prospectively by using a community sample there is no basis for comparing our results with a study that used a similar methodological approach. But, taking into account studies using clinical samples, some of the risk factor results obtained in our study are consistent with those found in previous research. Thus, Gureje and Simon [11] also found an association between preexisting depression and the onset of new somatization according to SSI4,6 over a 12-month follow-up period. Likewise, other previous research also suggests that specifically traumatic sexual experiences may increase the risk for later somatization in women $[4,24,33]$. 
Persistence was related to being female, prior substance use, affective and eating disorders as well as the prior experience of a traumatic event, specifically a serious accident. Thus, both the persistence and incidence of somatoform conditions share some identical risk factors as they both relate to female gender, and the experience of substance use and affective disorders at baseline. Risk factors that are associated with onset but not with persistence of somatization include social class and education, anxiety disorders and specifically traumatic sexual events. It seems to be possible that, for example, anxiety disorders or the experience of traumatic sexual events sensitizes to the perception of bodily sensations, but, once somatic symptoms are manifested, their stability seems to depend on conditions other than anxiety.

\section{Conclusion}

Our results suggest that somatoform disorders/ syndromes are highly prevalent even among younger age groups. At least for a substantial proportion of individuals, the overall picture of somatization seems to be relatively stable, but with fluctuation in the symptom picture over time. Being female, the experience of substance use as well as anxiety disorders seem to constitute risk factors for the onset of new somatoform conditions as well as for a stable course over time.

Table I. Prevalence of somatoform disorders at baseline among 14- to 24-year-olds and 42 months cumulative incidence.

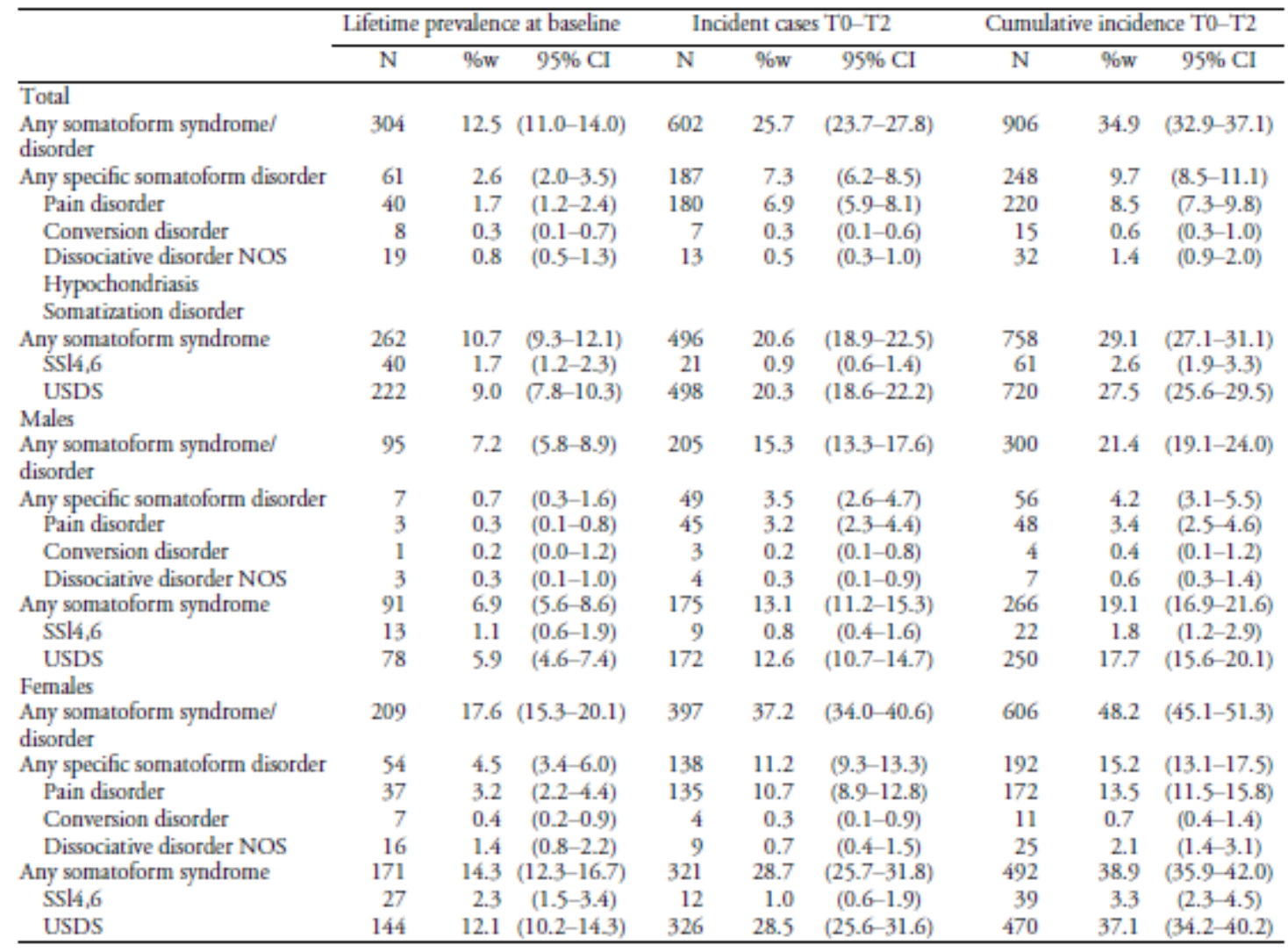

$N$ - weighted number, \%w - weighted percentage; $\mathrm{Cl}$ - confidence interval. 
Table II. Stability and transitions of somatoform disorders from baseline (TO) to follow-up (T2).

\begin{tabular}{|c|c|c|c|c|c|c|c|c|c|c|c|c|c|c|c|c|c|c|}
\hline \multirow[b]{4}{*}{ Diagonostic status T0 } & \multicolumn{18}{|c|}{ Conditional probabilities (follow-up T2) } \\
\hline & & & \multicolumn{10}{|c|}{ Specific somatoform disorder/syndrome } & \multicolumn{6}{|c|}{ Aggregate } \\
\hline & \multicolumn{2}{|c|}{$\begin{array}{c}\text { No Som. } \\
\text { DX/Syndrome }\end{array}$} & \multicolumn{2}{|c|}{$\begin{array}{c}\text { Pain } \\
\text { disorder }\end{array}$} & \multicolumn{2}{|c|}{$\begin{array}{l}\text { Conversion } \\
\text { disorder }\end{array}$} & \multicolumn{2}{|c|}{$\begin{array}{l}\text { Dissociative } \\
\text { disorder } \\
\text { NOS } \\
\end{array}$} & \multicolumn{2}{|c|}{ SSI4,6 } & \multicolumn{2}{|c|}{ USDS } & \multicolumn{2}{|c|}{$\begin{array}{c}\text { Any } \\
\text { disorder/ } \\
\text { syndrome }\end{array}$} & \multicolumn{2}{|c|}{$\begin{array}{c}\text { Any } \\
\text { disorder }\end{array}$} & \multicolumn{2}{|c|}{$\begin{array}{c}\text { Any } \\
\text { syndrome }\end{array}$} \\
\hline & $N$ & \%w & $N$ & $96 \mathrm{w}$ & $N$ & \%w & $N$ & \%w & $N$ & \%w & $N$ & $\% w$ & $N$ & \%कw & $N$ & \%w & $N$ & \%कw \\
\hline \multicolumn{19}{|l|}{ Specific somatoform disorder } \\
\hline Pain disorder $(N-40)$ & 14 & 34.5 & 12 & 29.7 & - & - & - & - & - & - & 18 & 44.1 & 26 & 65.5 & 12 & 29.7 & 18 & 44.1 \\
\hline Conversion disorder $(N-8)$ & 1 & 10.6 & 2 & 19.0 & - & - & 1 & 6.3 & - & - & & 70.5 & & 89.4 & 3 & 25.2 & 5 & 70.5 \\
\hline $\begin{array}{l}\text { Dissociative disorder NOS } \\
(N-19)\end{array}$ & 10 & 53.6 & 2 & 7.2 & - & - & - & - & - & - & & 39.2 & & 46.4 & 2 & 7.2 & 7. & 39.2 \\
\hline \multicolumn{19}{|l|}{ Somatoform syndrome } \\
\hline SSI $4,6(N-40)$ & 10 & 25.7 & 11 & 24.5 & 2 & 5.7 & 2 & 5.9 & 6 & 16.3 & 17 & 433 & 30 & 74.3 & 12 & 29.9 & 23 & 59.6 \\
\hline USDS $(N-222)$ & 132 & 58.6 & 15 & 7.1 & - & - & 2 & 1.0 & 3 & 1.7 & 75 & 34.0 & 90 & 41.4 & 17 & 8.2 & 77 & 35.6 \\
\hline \multicolumn{19}{|l|}{ Aggregate } \\
\hline $\begin{array}{l}\text { Any somatoform disorder or } \\
\text { syndrome }(N-304)\end{array}$ & 160 & 51.7 & 36 & 12.1 & 2 & 0.8 & 5 & 1.7 & 9 & 3.4 & 110 & 363 & 144 & 48.3 & 40 & 13.3 & 118 & 39.6 \\
\hline $\begin{array}{l}\text { Any somatoform disorder } \\
(N-61)\end{array}$ & 24 & 39.2 & 15 & 23.0 & - & - & 1 & 0.7 & - & - & 26 & 43.2 & 37 & 60.8 & 16 & 23.7 & 26 & 43.2 \\
\hline $\begin{array}{l}\text { Any somatoform syndrome } \\
(N-262)\end{array}$ & 142 & 53.4 & 26 & 9.9 & 2 & 0.9 & 4 & 1.8 & 9 & 4.0 & 92 & 35.5 & 120 & 46.6 & 29 & 11.1 & 100 & 39.3 \\
\hline
\end{tabular}

$N$ - unweighted number; \%w - weighted percentage.

As conversion disorder and dissociative disorder NOS were not defined as mutually exclusive, the sum of the $N$ values for the specific disorders does not always equal the $N$ values for the groups.

SSI - somatic symptom index; USDS: undifferentiated somatoform/dissociative syndrome.

Table III. Baseline factors associated with new onsets and persistence of any somatoform disorder/syndrome over the 4-year follow-up period.

\begin{tabular}{|c|c|c|c|c|}
\hline \multirow[b]{2}{*}{ Baseline factor } & \multicolumn{2}{|c|}{$\begin{array}{l}\text { Incidence }^{1} \\
(N-602)\end{array}$} & \multicolumn{2}{|c|}{$\begin{array}{l}\text { Stability }^{2} \\
(N-144)\end{array}$} \\
\hline & OR & $95 \% \mathrm{Cl}$ & OR & $95 \% \mathrm{CI}$ \\
\hline Age at baseline & 0.9 & $(0.91-0.97)$ & 0.9 & $(0.90-1.07)$ \\
\hline \multicolumn{5}{|l|}{ Gender } \\
\hline Male & 1.0 & & 1.0 & \\
\hline Female & $3.3^{*}$ & $(2.64-4.09)$ & $2.2^{*}$ & $(1.26-3.89)$ \\
\hline \multicolumn{5}{|l|}{ Social dass } \\
\hline Low & 1.0 & & 1.0 & \\
\hline Middle & 0.7 & $(0.42-1.00)$ & 0.9 & $(0.34-2.33)$ \\
\hline High & $0.5^{*}$ & $(0.31-0.78)$ & 1.0 & $(0.39-2.65)$ \\
\hline \multicolumn{5}{|l|}{ Educational level } \\
\hline Hauptschule & 1.0 & & 1.0 & \\
\hline Real/Fachoberschule & 0.8 & $(0.57-1.19)$ & 0.8 & $(0.31-2.08)$ \\
\hline Gymnasium & $0.6^{*}$ & $(0.45-0.88)$ & 1.1 & $(0.49-2.55)$ \\
\hline University & 0.6 & $(0.28-1.36)$ & 1.7 & $(0.26-11.01)$ \\
\hline \multicolumn{5}{|l|}{ Psychopathology $y^{3}$} \\
\hline Any substance use disorder & $1.5^{*}$ & (1.14-1.94) & $1.8^{*}$ & $(1.08-3.12)$ \\
\hline Any anxiety disorder & $1.8^{*}$ & $(1.42-2.34)$ & 1.4 & $(0.80-2.46)$ \\
\hline Any affective disorder & $2.0^{*}$ & (1.50-2.69) & $1.9^{*}$ & (1.06-3.53) \\
\hline Any eating disorder & 1.5 & $(0.72-3.14)$ & $4.0^{*}$ & $(1.30-12.21)$ \\
\hline \multicolumn{5}{|l|}{ Early traumatic events ${ }^{4}$} \\
\hline Rape/sexual abuse & $2.8^{*}$ & $(1.43-5.48)$ & 3.1 & $(0.79-12.09)$ \\
\hline Physical threat & $1.9^{*}$ & $(1.28-2.87)$ & 1.3 & $(0.59-2.95)$ \\
\hline Serious accident & 1.4 & $(0.92-2.14)$ & $2.7^{*}$ & $(1.07-6.87)$ \\
\hline Any traumatic event & $1.8^{*}$ & $(1.34-2.39)$ & 1.2 & $(0.69-2.21)$ \\
\hline
\end{tabular}

$* P<0.05$; OR indicates odds ratio; all odds ratios are controlled for age and gender.

${ }^{1}$ Reference group: respondents with no diagnosis of any somatoform disorder/syndrome at baseline who reported no diagnosis again during follow-up.

${ }^{2}$ Reference group: respondents with the diagnosis of any somatoform disorder/syndrome at baseline who remitted during follow-up.

3 "Any substance use disorder" indudes alcohol abuse and dependence, nicotine dependence and abuse/dependence of illicit drugs.

"Any anxiety disorder" indudes generalized anxiety disorder, panic disorder, agoraphobia w/o panic disorder, social phobia, specific phobia, phobia NOS, obsessive compulsive disorder and post-traumatic stress disorder.

"Any affective disorder" indudes major depression, dysthymia and bipolar disorders.

"Any eating disorder" indudes anorexia nervosa, atypical anorexia nervosa, bulimia nervosa and atypical bulimia nervosa.

${ }^{4}$ Early traumatic events were assessed within the posttraumatic-stress-disorder-section of the M-CIDI.

"Any traumatic event" includes rape/sexual abuse, serious accident, victim of natural catastrophe, war experience, physical threat, having been imprisoned, hostage, victim of kidnapping, having been witness of one of the events that happened to another person. 


\section{Acknowledgements}

This work is part of the Early Developmental Stages of Psychopathology (EDSP) Study and is funded by the German Ministry of Research and Technology, project no. 01 EB 9405/6 and 01 EB 9901/6. Principal investigators are Dr. Hans-Ulrich Wittchen and Dr. Roselind Lieb. Current or former staff members of the EDSP group are Dr. Kirsten von Sydow, Dr. Gabriele Lachner, Dr. Axel Perkonigg, Dr. Peter Schuster, Dr. Franz Gander, Dipl.-Stat. Michael Höfler and Dipl.-Psych. Holger Sonntag as well as Mag. phil. Esther Beloch, Mag. rer. nat. Martina Fuetsch, Dipl.-Psych. Elzbieta Garczynski, Dipl.-Psych. AlexandraHolly,Dipl.-Psych. Barbara Isensee, Dipl.-Psych. Marianne Mastaler, Dr. Chris Nelson, Dipl.-Inf. Hildegard Pfister, Dr. Victoria Reed, Dipl.-Psych. Andrea Schreier, Dipl.-Psych. Dilek Türk, Dipl.-Psych. Antonia Vossen, Dr. Ursula Wunderlich and Dipl.-Psych. Petra Zimmermann. Scientific advisors are Dr. Jules Angst (Zurich), Dr. Jürgen Margraf (Basel), Dr. Günther Esser (Potsdam), Dr. Kathleen Merikangas (Yale, New Haven) and Dr. Ron Kessler (Harvard, Boston).

\section{References}

1 American Psychiatric Association: Diagnostic and Statistical Manual of Mental Disorders. 4th ed. Washington D.C.: American Psychiatric Association; 1994.

2 Aro H, Paronen O, Aro S. Psychosomatic symptoms among 14-16-year-old Finnish adolescents. Soc Psychiatry 1987;22: 171-6.

3 Barsky AJ, Fama JM, Bailey AD, Ahern DK. A prospective 4- to 5-year study of DSM-III-R hypochondriasis. Arch Gen Psychiatry 1998;55:737-44.

4 Barsky AJ, Wool C, Barnett MC, Cleary PD. Histories of childhood trauma in adult hypochondriacal patients. Am J Psychiatry 1994;151(3):397-401.

5 Bland RC, Newman SC, Orn H. Period prevalence of psychiatric disorders in Edmonton. Acta Psychiatr Scand 1988; 77(Suppl 338):33-42.

6 Escobar JI, Burnam MA, Karno M, Forsythe A, Golding JM. Somatization in the community. Arch Gen Psychiatry 1987; 44:713-8.

7 Escobar JI, Gara M, Silver RC, Waitzkin H, Holman A, Compton W. Somatization disorder in primary care. Br J Psychiatry 1998;173:262-6.

8 Escobar JI, Rubio-Stipec M, Canino G, Karno M. Somatic symptom index (SSI): a new and abridged somatization construct. J Nerv Ment Dis 1989;177:140-6.

9 Essau C, Conradt J, Petermann F. Häufigkeit und Komorbidität somatoformer Störungen bei Jugendlichen: Ergebnisse der Bremer Jugendstudie. Zeitschr Klin Psychol Psychother 2000; 29(2):97_ 108.

10 Garber J, Walker LS, Zeman J. Somatization symptoms in a community sample of children and adolescents: further valida-tion of the Children's Somatization Inventory. J Consult Clin Psychol 1991;3:588-95.

11 Gureje O, Simon GE. The natural history of somatization in primary care. Psychol Med 1999;29:669-76.

12 Hwu HG, Yeh EK, Chang LY. Prevalence of psychiatric disorders in Taiwan defined by the Chinese Diagnostic Interview Schedule. Acta Psychiatr Scand 1989;79:136-47.

13 Höfler M, Lieb R, Perkonigg A, Schuster P, Sonntag H, Wittchen H-U. Covariates of cannabis use progression in a representative population sample of adolescents: a prospective examination of vulnerability and risk factors. Addict 1999; 94(11):1679-94.

14 Katon W, Lin E, Korff von M, Russo J, Lipscomb P, Bush T. Somatization: a spectrum of severity. Am J Psychiatry 1991; 148:34-40.

15 Kent DA, Tomasson K, Coryell W. Course and outcome of conversion and somatization disorders - a 4-year follow-up. Psychosom 1995;36(2):138-44.

16 Kroenke K, Price RK. Symptoms in the community. Prevalence, classification, and psychiatric comorbidity. Arch Intern Med 1993;153:2474-80.

17 Kroenke K, Spitzer RL. Gender differences in the reporting of physical and somatoform symptoms. Psychosom Med 1998; 60:150-5. 
18 Kroenke K, Spitzer RL, Degruy F, Hahn SR, Linzer M, Williams JB, et al. Multisomatoform disorder. An alternative to undifferentiated somatoform disorder for the somatising patient in primary care. Arch Gen Psychiatry 1997;100:352-8.

19 Lachner G, Wittchen HU, Perkonigg A, Holly A, Schuster P, Wunderlich U, et al. Structure, content and reliability of the Munich-Composite International Diagnostic Interview (M-CIDI). Substance use sections. Eur Addict Res 1998; 4(1-2):28-41.

20 Lieb R, Mastaler M, Wittchen H-U. Gibt es somatoforme Störungen bei Jugendlichen und jungen Erwachsenen? Erste epidemiologische Befunde der Untersuchung einer bevölkerungsrepräsentativen Stichprobe. Verhaltenstherapie - Praxis Forschung Perspektiven 1998;8:81-93.

21 Lieb R, Pfister H, Mastaler M, Wittchen H- U. Somatoform syndromes and disorders in a representative population sample of adolescents and young adults: prevalence, comorbidity and impairments. Acta Psychiatr Scand 2000;101:194-208.

22 Lieb R, Isensee B, Sydow von K, Wittchen HU. The early developmental stages of psychopathology study (EDSP), a methodological update. Eur Addict Res 2000;6:170-82.

23 Perkonigg A, Kessler RC, Storz S, Wittchen H- U. Traumatic events and posttraumatic stress disorder in the community: prevalence, risk factors and comorbidity. Acta Psychiatr Scand 2000;101:46-59.

24 Pribor EF, Yutzy SH, Dean T, Wetzel RD. Briquet's syndrome, dissociation, and abuse. Am J Psychiatry 1993;150: 1507-11.

25 Reed V, Gander F, Pfister H, Steiger A, Sonntag H, Trenkwalder C, et al. To what degree the Composite International Diagnostic Interview (CIDI) correctly identifies DSM-IV disorders? Testing validity issues in a clinical sample. Int J Meth Psychiatr Res 1998;7(3):142-55.

26 Regier DA, Boyd JH, Burke Jr JD, Rae DS, Myers JK, Kramer M, et al. One month prevalence of mental disorders in the United States. Arch Gen Psychiatry 1988;45:977-86.

27 Rief W, Hessel A, Braehler E. Somatization symptoms and hypochondriacal features in the general population. Psychosom Med 2001;63(4):595-602.

28 Royall RM. Model robust confidence intervals using maximum likelihood estimators. Int Statist Rev 1986;54:221-6.

29 Simon GE, Gureje O. Stability of somatization disorder and somatization symptoms among primary care patients. Arch Gen Psychiatry 1999;56:90-5.

30 Stata Corp: Stata Statistical Software: Release 7.0. College Station, TX: Stata Corporation. 2001. 31 Stein MB, Fuetsch M, Müller N, Höfler M, Lieb R, Wittchen H- U. Social anxiety disorder and the risk of depression. A prospective community study of adolescents and young adults. Arch Gen Psychiatry 2001;58:251-6.

32 Swartz M, Blazer D, George L, Landerman R. Somatization in a community population. Am J Psychiatry 1986;143:1403-8.

33 Walker EA, Katon WJ,Hansom J, Harrop-Griffiths J, Holm L, Jones ML, et al. Medical and psychiatric symptoms in women with childhood sexual abuse. Psychosom Med 1992;54: 658-64.

34 Wells JE, Bushnell JA, Hornblow AR, Joyce PR, Oakley-Browne MA. Christchurch psychiatric epidemiology study, I: methodology and lifetime prevalence for specific psychiatric disorders. Aust New Zealand J Psychiatry 1989;23:315-26.

35 Wittchen H-U, Essau CA, Zerssen von D, Krieg CJ, Zaudig M. Lifetime and six-month prevalence of mental disorders in the Munich follow-up study. Eur Arch Psychiatr Clin Neurosci 1992;241:24758.

36 Wittchen H- U, Lachner G, Wunderlich U, Pfister H. Test-retest reliability of the computerized DSM-IV version of the Munich-Composite International Diagnostic Interview (M-CIDI). Soc Psychiatry Psychiatr Epidemiol 1998;33: 568-78.

37 Wittchen HU, Lieb R, Pfister H, Schuster P. The waxing and waning of mental disorders: evaluating the stability of syndromes of mental disorders in the population. Comprehensive Psychiatry 2000;41:122-32.

38 Wittchen H-U, Lieb R, Schuster P, Oldehinkel T. When is onset? Investigations into early developmental stages of anxiety and depressive disorders. In: Rapoport JL, editor. Childhood onset of "adult" psychopathology, clinical and research advances. Washington D.C.: American Psychiatric Press; 1999. p. 259-302.

39 Wittchen H-U, Perkonigg A, Lachner G, Nelson CB. Early developmental stages of psychopathology study (EDSP): objectives and design. Eur Addict Res 1998;4(1-2):18-27. 
40 Wittchen HU, Pfister H, editors. DIA-X-Interviews: Manual für Screening-Verfahren und Interview; Interviewheft Längsschnittuntersuchung (DIA-X-Lifetime); Ergänzungsheft (DIA-XLifetime); Interviewheft Querschnittuntersuchung (DIA-X-12 Monate); Ergänzungsheft (DIA-X-12 Monate); PC-Programm zur Durchführung des Interviews (Längs- und Querschnittuntersuchung); Auswertungsprogramm. Frankfurt: Swets and Zeitlinger; 1997.

41 Wool CA, Barsky AJ. Do women somatize more than men? Psychosom 1994;35:445-52. 